\title{
Biomarkers of Aging in HIV: Inflammation and the Microbiome
}

\author{
Camilla Tincati $^{1}$, Esther Merlini ${ }^{1}$ Giuseppe Ancona ${ }^{1}$ and Giulia Marchetti ${ }^{1}$
}

\author{
${ }^{1}$ Department of Health Sciences, Clinic of Infectious Diseases, ASST Santi Paolo e Carlo, \\ University of Milan, Italy
}

Correspondence to: Camilla Tincati, M.D., Ph.D.

Address: Clinic of Infectious Diseases, Department of Health Sciences, University of Milan, San Paolo Hospital, Milan, Italy, Via di Rudini’ 8, 20142, Milan, Italy

Phone: +390281843046; Fax: +390281843054; Email: camilla.tincati@unimi.it

\section{Acknowledgements}

This work was supported by the Italian Ministry of Health, Regione Lombardia, grant "Giovani Ricercatori" (number GR-2009-1592029; PI: GM) and grant "Ricerca Finalizzata-Progetti di Rete" (number NET-2013-02355333-3; PI: GM). 


\begin{abstract}
Purpose

HIV-infected subjects present increased levels of inflammatory cytokines and T-cell activation in the peripheral blood despite suppressive combination antiretroviral therapy which renders them at increased risk of premature aging. The purpose of the present work is to review existing evidence on the ways in which the anatomical and microbiological abnormalities of the gastrointestinal tract can represent a major cause of organ disease in HIV infection.
\end{abstract}

\title{
Methods
}

We conducted a systematic review of the Pubmed database for articles published from 2014 to 2018. We included studies on inflammatory/activation biomarkers associated with cardiovascular and bone disease, neurocognitive impairment and serious non-AIDS events in HIV-infected subjects. We also included researches which linked peripheral inflammation/activation to the anatomical, immune and microbiological alterations of the gastrointestinal tract.

\section{Results}

Recent literature data confirm the association between non-infectious comorbidities and inflammation in HIV infection which may be driven by gastrointestinal tract abnormalities, specifically microbial translocation and dysbiosis. Furthermore, there is mounting evidence on the possible role of metabolic functions of the microbiota in the pathogenesis of premature aging in the HIV-infected population

\section{Conclusions}

Biomarkers need to be validated for their use in the management of HIV infection. Compounds which counteract microbial translocation, inflammation and dysbiosis have been investigated as alternative therapeutic strategies in viro-suppressed HIV-infected individuals, but appear to have limited efficacy, probably due to the multifactorial pathogenesis of non-infectious comorbidities in this setting. 


\section{Keywords}

HIV, inflammation, comorbidities, microbial translocation, microbiome, metabolome 


\section{HIV, inflammation and end-organ disease}

Infection with the Human Immunodeficiency Virus (HIV) can be considered an inflammatory disease [1]. If left untreated, viral replication leads to the loss of CD4+ T-cell counts and HIV infection progresses to the Acquired Immunodeficiency Syndrome (AIDS). Combination antiretroviral therapy (cART), i.e. the combined use of three, effective antiviral drugs which impede HIV replication, has drastically changed the natural course of infection by restoring CD4+ T-cell counts and hampering advancement of HIV-infected subjects to AIDS [2]. Literature has consistently shown, however, that inflammation and activation persist in the course of virosuppressive treatment, albeit at lower levels than those observed when the infection remains untreated [1]. Specifically, HIV-infected subjects on cART feature activation of innate (sCD14, sCD163) and adaptive (CD38+HLADR+) immunity, senescent immune phenotypes (low expression levels of CD28, elevated levels of CD57 and PD-1), impaired thymic output, persistence of HIV reservoirs, reduced antigen-specific responses and heightened levels of pro-inflammatory and coagulation markers (IL-6, d-dimer, high-sensitivity C Reactive Protein, CRP) [1]. Interestingly, such chronic, low-grade inflammation presents immune abnormalities that characterize physiologic aging [3]. The so called "inflammaging" signature of viro-suppressed, HIV-infected subjects renders this population at risk of premature aging (cardiovascular, bone and renal disease as well as neurocognitive impairment) and death from non-infectious comorbidities $[3]$.

Inflammatory and activation biomarkers have been object of numerous studies for their exploitation in clinical practice in order to aid in the identification and management of HIV-infected subjects at risk of non-communicable diseases $[4,5]$. Yet, despite these efforts, the lack of validation standards for the majority of biomarkers investigated and the multifactorial process behind it [6] are causing a dearth of parameters to support clinicians in their decisions.

Microbial translocation from the gut lumen to the systemic circulation has been widely investigated as one of the possible causes of activation/inflammation linked to premature aging in HIV infection 
[6]; furthermore, it triggered studies on the gastrointestinal tract as a major site of HIV pathogenesis and shed light on possible mechanisms to target for the elaboration of alternative therapeutic interventions [1].

The purpose of the present work is to review existing evidence on the ways in which the anatomical and microbiological abnormalities of the gastrointestinal tract can represent a major cause of organ disease in HIV infection.

Microbial translocation-induced immune activation and inflammation are linked to noninfectious comorbidities in HIV infection

Microbial translocation, i.e. the passage of bacteria and microbial bioproducts (e.g. lipopolysaccharide, LPS, of Gram-negative microrganisms) through the gastrointestinal tract to the peripheral circulation, is a major cause of immune activation in HIV infection.

Over a decade go, a seminal paper by Brenchley et al. described increased plasma levels of LPS in HIV-infected subjects and demonstrated their positive correlation with markers of innate and adaptive immunity [7]. Subsequent literature observations confirmed such finding and demonstrated high levels of microbial-induced immune activation in subjects with poor CD4+ T-cell recovery on cART $[8,9]$ as well as non-infectious comorbidities.

In this respect, microbial translocation, inflammation and immune activation have been invariably associated with cardiovascular risk in the HIV-infected population [10]. In particular, various parameters have been linked to dyslipidemia [11-13], insulin insensitivity [11, 12], endothelial dysfunction [14], visceral fat accumulation, higher Framingham risk [11, 12, 15], subclinical artery disease [16-20] and biomarkers of cardiovascular disease in this setting [12], highlighting the possible common pathways that cardiovascular disease and HIV share in their pathogenesis.

Similarly, osteopenia and osteoporosis in HIV-positive subjects may be driven by the inflamed and activated immune milieu which features infection [21-25]. While some reports confirm the association between immune biomarkers and impaired osteogenesis [25, 26]/mineral density [27, 
28], others have however failed to detect such a link [29, 30]. Future studies are thus warranted to explore the true effects of activation/inflammation on bone mineral density and fractures in the HIV-infected population.

More recently, inflammatory biomarkers have also been studied in the context of HIV-related neurocognitive disorders. A growing body of evidence shows that immune-mediated brain injury may contribute to cognitive impairment and structural brain abnormalities [31-36]. The clinical significance of these findings remains yet an open matter, as central nervous system activation and inflammation also feature asymptomatic individuals [37-39].

Finally, large cohort studies confirmed the above-mentioned findings by demonstrating that markers of microbial translocation (LPS,), immune activation (sCD14), inflammation (IL-6, sTNFRI, sTNF-RII, high-sensitivity CRP) and coagulation (d-dimer and sICAM-1) are independent predictors of mortality as well as AIDS and non-AIDS related morbidity in HIV infection [40-45].

The most recent findings on biomarkers predicting non-infectious comorbidities, serious non-AIDS events (SNAEs) and death in cART-treated subjects are summarized in Table 1.

\section{The gut as a source of inflammation in HIV infection}

Suggestive evidence of microbial translocation being a cause of immune activation prompted the indepth study of the gut as a pathogenic site of HIV infection.

At the very beginning of the epidemic HIV-related enteropathy with malabsorption and steathorrea in untreated individuals was described in literature and featured both jejunal (partial villus atrophy with crypt hyperplasia) and colonic abnormalities (focal cell degeneration near the crypt base) [46]. More recently, studies have shed light on the underlying mechanisms of HIV-related enteropathy by demonstrating that exposure of genital and intestinal epithelial cells to HIV can directly breach the integrity of mucosal epithelial barrier allowing for microbial translocation [47]. Furthermore, in the context of untreated infection, microbial-induced immune activation, measured by the levels of 
soluble CD14 (sCD14) correlated with markers of intestinal damage, thus pointing to the gut as a possible source of systemic inflammation [48].

A solid bulk of evidence demonstrated that the anatomical defects of HIV-related enteropathy persist on cART. Indeed, a reduced expression of ileum and colonic gut junctional complex proteins (cadherins, claudins, occludins) features long-term treated subjects [49-51] and is linked to increased gut permeability and persistent levels of microbial translocation [51]. Moreover, the negative correlation between LPS-dependent immune activation (sCD14 plasma levels, peripheral $\mathrm{CD}^{+} \mathrm{CD} 38^{+} \mathrm{T}$-cell frequencies) and gut junctional proteins $[49,51]$ further highlights that GI tract defects may contribute to inflammation. In line with this finding, a cohort study showed that peripheral blood levels of intestinal fatty acid binding protein, marker of intestinal damage, and zonulin-1 are independent predictors of mortality in cART-treated subjects [52].

Another important alteration that occurs in the gastrointestinal tract which may fuel microbial translocation is the impairment of mucosal immunity: early studies highlighted the massive depletion of CD4+ T-cell at mucosal sites in all phases of HIV infection and their partial reconstitution in the course of treatment [46]. More recently, studies have focused on cell populations which safeguard mucosal surfaces, namely IL-17-producing subsets: indeed, IL-17 is a crucial cytokine for protection against infectious microbes [53] and epithelial maintenance occurs through wound repair [54-56]. Both innate $(\gamma \delta \mathrm{T})$ and adaptive (Th) IL-17 producing cells are lost in the natural course of HIV infection [57, 58]; while their frequencies may be restored by the introduction of early treatment, their function invariably remains impaired [46], thus possibly explaining the persistence of microbial translocation and structural defects of the gastrointestinal tract despite effective therapy. Many reports have indeed confirmed the inverse relationship between IL-17-producing cell frequencies and inflammation in untreated disease [46], yet whether functional defects of mucosal populations directly drive inflammation and activation in the periphery of subjects on cART has yet to be demonstrated. 
Findings on impaired gut structure and mucosal immunity in the setting of HIV infection have prompted the study of the gut microbiota, given its role in the maturation of the gut barrier and control of immune homeostasis at mucosal sites [57].

Early reports in naïve subjects identified an outgrowth of fecal P.aeurginosa and C. albicans as well as a reduction of bifidobacteria and lactobacilli; these alterations were linked to increased fecal calprotectin levels, marker of intestinal inflammation [46]. Subsequent studies confirmed a dysbiotic fecal microbiota in the course of HIV infection featuring the enrichment for Proteobacteria and skewing of the Bacteroidetes phylum with a Prevotella-rich/Bacteroides-poor profile [59-64], which is only partially restored by cART [65]. Importantly, HIV-related dysbiosis correlates with heightened T-cell and myeloid dendritic cell activation, lower mucosal IL-17/IL-22 secretion, as well as inflammatory markers $[59,61]$. In the attempt to demonstrate the mechanisms whereby the fecal microbiota causes peripheral T-cell activation and inflammation, a very recent study reported greater production of pro-inflammatory cytokines in monocyte cultures (TNF-a, IL6, IFN- $\gamma$ ) and the selective activation of peripheral T-cells following culture stimulation with fecal bacterial communities in HIV infection [66].

Taken together, literature studies convene that HIV-related dysbiosis may drive peripheral blood inflammation and may be thus implicated in organ disease.

\section{The metabolic pathways of a dysbiotic microbiome may drive inflammation and organ disease in HIV infection}

Technical advances have not only shed light on the composition of resident bacteria in HIV infection but also on the functional activity of the microbiota, which is critical to human health and disease [67].

An early study showed differences between the relative abundance of several imputed metagenomic functions between untreated HIV-infected subjects and healthy controls, suggesting the impairment of the functional activity of the microbiota in HIV infection [68]. In line with this observation, 
researches that followed showed that the microbiota is depleted in genes belonging to main energetic processes (pyruvate metabolism, glycolysis and gluconeogenesis) and amino acid metabolism [63] which could impact on cART-mediated reconstitution of CD4+ T-cells [69]. In addition, bacterial genera enriched in HIV-infected, untreated subjects were found to encode enzymes involved in tryptophan catabolism [70, 71], an independent predictor of non-AIDS comorbidities and death $[52,72]$, thus entailing that the dysbiotic bacteria in HIV infection may directly contribute to immunoactive tryptophan catabolism in HIV and negatively impact on overall mortality [70].

Stemming from these findings, other intestinal microbiota-generated metabolites known to cause organ disease were explored in the setting of non-infectious comorbidties in HIV infection. In particular, trimethylamine-N-oxide (TMAO), a metabolite of phosphatidylcholine, was linked to plaque burden [73, 74], myocardial perfusion defects [75], coronary stenosis [76] in HIV-infected subjects. Although TMAO was independently associated with microbial translocation markers (LPS) [77] and macrophage activation (sCD14, CD163) [74, 77], a recent report failed to find a relationship between the metabolite and inflammation [78], suggesting its limited use as clinical marker of cardiovascular risk in HIV infection given possible confounders.

Significant evidence exists in literature on the gut-brain axis, i.e. the bidirectional communication between the central and the enteric nervous system, linking emotional and cognitive centers of the brain with peripheral intestinal functions [79]. The production of bacterial metabolites represents a possible mechanism by which the intestinal microbiota interacts with the brain. In the setting of HIV infection, increased choline and $\mathrm{N}$-acetyl aspartate were recently found in the brain of subjects with neurocognitive impairment [80]; with evidence currently lacking on the source of such metabolites, future studies are critical for addressing whether microbial-dependent metabolites play a role in the pathogenesis of neurocognitive disorders in HIV infection.

In line with the findings of a link between the microbiota and the central nervous system, studies in the clinical setting of rheumatoid arthritis and inflammatory bowel disease have demonstrated the 
existence of a gut-immune-skeletal axis in which alteration of the gut microbione induce an activated immune phenotype and inflammatory milieu which associates with bone loss [81]. Given the pathogenic and clinical features of HIV disease, further research should explore the effects of the microbiome/metabolome in HIV-relates osteopenia and osteoporosis.

\section{Open issues and future directions}

The present review focused on microbial translocation-induced activation and inflammation as a cause of premature aging in HIV disease. We highlighted the role of the gastrointestinal tract as a driver of inflammation: alterations of the gut epithelial barrier, mucosal immune populations and microbiome/metabolome all play a key role in causing and perpetuating low-grade inflammation which features the inflammaging phenotype of viro-suppressed HIV-infected individuals.

Clinical questions remain as to whether any on the inflammatory biomarkers examined in the literature may be used as a screening tool to identify subjects at risk of developing non-infectious comorbidities. Inflammatory biomarkers lack validation standards and are not routinely measured in HIV-infected individuals; this leaves clinicians with the CD4+ T-cell count as the only reliable marker to assess subjects' immune status, which nonetheless does not capture the "inflammaging" signature of cART-treated disease. Studies focusing on longitudinal cohorts with powered clinical endpoints are needed in order to exploit biomarkers of premature aging in the clinical practice.

Another relevant aspect is how to turn-off microbial-driven inflammation. In this respect, work has been carried out in the attempt to reverse microbial translocation and dysbiosis. In humans, LPSantagonizing compounds (sevelamer), anti-inflammatory agents (mesalamine) and antibiotics (rifaximin) have lead to little/no effects on microbial translocation, inflammation and T-cell activation [46]. Similarly, the administration of pre/probiotics did not result in significant changes in inflammation/activation [46] and composition of the microbiome [82]. A possible explanation for the failure of these treatments is that they target a limited set of causes underlying a multifactorial process (i.e. microbial translocation, reservoirs, CMV co-infection) [6]. Future studies should aim at 
combining several approaches in order to counteract the complex phenomenon of aging in HIV infection. 
Table 1: Biomarkers linked to non-infectious comorbidities, serious non-AIDS events and death in cART-treated, HIV-infected subjects

\begin{tabular}{|c|c|c|c|c|c|c|}
\hline Clinical Event & Study design & Patient Population & Aim & Markers & Main findings & Reference \\
\hline CVD & Cross-sectional & 61 cART-treated & \begin{tabular}{lcr} 
Investigate & whether & microbial \\
translocation & and & monocyte \\
activation & associate & with \\
endovascular & \multicolumn{2}{c}{ dysfunction, } \\
inflammation & and & altered \\
coagulation. & & \\
\end{tabular} & $\begin{array}{l}\text { LPS, sCD14, hs- } \\
\text { CRP, d-dimer }\end{array}$ & $\begin{array}{l}\text { sCD14 associates with } \\
\text { endovascular dysfunction } \\
\text { in HIV. }\end{array}$ & [14] \\
\hline CVD & Cross-sectional & 147 cART-treated & 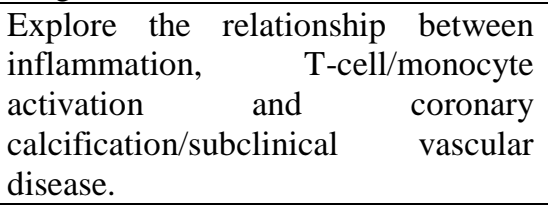 & $\begin{array}{l}\text { sCD14, sCD163, hs- } \\
\text { CRP, IL-6, sTNFR- } \\
\text { II, sVCAM-1, OPG, } \\
\text { RANKL }\end{array}$ & $\begin{array}{l}\text { SCD14 independently } \\
\text { associates with coronary } \\
\text { artery calcification. }\end{array}$ & [19] \\
\hline CVD & Cross-sectional & 252 cART-treated & $\begin{array}{l}\text { Explore the association of soluble } \\
\text { biomarkers with } \\
\text { demographics, HIV progressiont } \\
\text { components of the metabolic } \\
\text { syndrome, viral co-infections, } \\
\text { Framingham risk score and the } \\
\text { VACS Index. }\end{array}$ & $\begin{array}{l}\text { IL-6, cystatin C, hs- } \\
\text { CRP, TNF- } \alpha, \quad \text { d- } \\
\text { dimer }\end{array}$ & 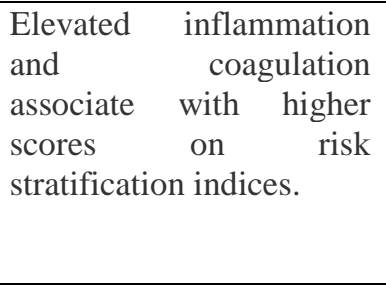 & {$[15]$} \\
\hline CVD & Cross-sectional & $\begin{array}{l}242 \text { cART-treated and } \\
348 \text { uninfected controls }\end{array}$ & $\begin{array}{l}\text { Investigate the association of } \\
\text { inflammatory markers with } \\
\text { subclinical coronary artery disease. }\end{array}$ & $\begin{array}{l}\text { IL-6, sICAM-1, } \\
\text { fibrinogen, d-dimer, } \\
\text { hs-CRP, sTNFR I } \\
\text { and II }\end{array}$ & $\begin{array}{l}\text { Higher inflammatory } \\
\text { marker levels associated } \\
\text { with greater prevalence } \\
\text { of coronary stenosis. }\end{array}$ & [16] \\
\hline CVD & & 149 cART-treated & $\begin{array}{l}\text { Determine the associations of } \\
\text { markers of immune activation with } \\
\text { atherosclerosis and mortality. }\end{array}$ & $\begin{array}{l}\text { IL-6, hs-CRP, } \\
\text { sCD14, sCD163, d- } \\
\text { dimer, T cell } \\
\text { activation (HLA- } \\
\text { DR/CD38) and } \\
\text { senescence } \\
\text { (CD57/CD28), } \\
\text { monocytes subsets } \\
\text { (CCR2/CX3CR1 } \\
\text { /CCR5) }\end{array}$ & $\begin{array}{l}\text { Monocyte CCR5 } \\
\text { expression and plasma } \\
\text { IL-6 associate with } \\
\text { atherosclerosis. IL-6 and } \\
\text { carotid artery IMT } \\
\text { associate with all-cause } \\
\text { mortality. }\end{array}$ & {$[17]$} \\
\hline $\begin{array}{l}\text { CVD/Bone } \\
\text { disorders }\end{array}$ & Cross-sectional & $\begin{array}{l}94 \text { cART-treated and } 41 \\
\text { uninfected controls }\end{array}$ & $\begin{array}{l}\text { Investigate the role of traditional } \\
\text { factors, T-cell phenotype and } \\
\text { osteoprotegerin in bone and } \\
\text { cardiovascular disease. }\end{array}$ & $\begin{array}{l}\text { OPG, T cell } \\
\text { activation (HLA- } \\
\text { DR/CD38) and } \\
\text { senescence } \\
\text { (CD57/CD28) }\end{array}$ & $\begin{array}{l}\text { OPG and T-cell } \\
\text { activation/senescence } \\
\text { linked to bone and } \\
\text { cardiovascular disease. }\end{array}$ & {$[28]$} \\
\hline Bone disorders & Cross-sectional & 142 cART-treated & Determine the association between & RANKL, OPG, & Weak correlation & [29] \\
\hline
\end{tabular}




\begin{tabular}{|c|c|c|c|c|c|c|}
\hline & & & $\begin{array}{l}\text { bone health and inflammation, T-cell } \\
\text { activation, and monocyte activation. }\end{array}$ & $\begin{array}{l}\text { sVCAM-1, sICAM- } \\
1 \text {, IL-6, TNF- } \alpha \text {, } \\
\text { sTNFR I and II, hs- } \\
\text { CRP, d-dimer, } \\
\text { sCD14, sCD163 }\end{array}$ & $\begin{array}{l}\text { between BMD and } \\
\text { markers of } \\
\text { inflammation/immune } \\
\text { activation . Bone } \\
\text { resorption associated } \\
\text { with ICAM-1 } \\
\end{array}$ & \\
\hline $\begin{array}{l}\text { Neurogognitive } \\
\text { impairment }\end{array}$ & Longitudinal & 99 cART-treated & $\begin{array}{l}\text { Examine the relationship between } \\
\text { mild HAND and CSF NFL/neopterin. }\end{array}$ & Neopterin, NFL & $\begin{array}{l}\text { Mild HAND } \text { was } \\
\text { associates with increased } \\
\text { intrathecal immune } \\
\text { activation. }\end{array}$ & {$[35]$} \\
\hline $\begin{array}{l}\text { Neurogognitive } \\
\text { impairment }\end{array}$ & Cross-sectional & 41 cART-treated & $\begin{array}{l}\text { Investigate the role of cell-free } \\
\text { mitochondrial DNA in the CSF. }\end{array}$ & $\begin{array}{l}\text { mitochondrialDNA, } \\
\text { sCD14, TNF- } \alpha \text {, IL- } \\
6, \text { IL- } 8, \text { MCP-1, IP- } \\
10, \text { NFL }\end{array}$ & $\begin{array}{lr}\text { Higher } & \text { cell-free } \\
\text { mitochondrial } & \text { DNA is } \\
\text { associates } & \text { with } \\
\text { inflammation } & \\
\end{array}$ & [39] \\
\hline $\begin{array}{l}\text { Neurogognitive } \\
\text { Impairment }\end{array}$ & Longitudinal & $\begin{array}{l}51 \text { acutely-infected, cART- } \\
\text { treated and } 18 \text { uninfected } \\
\text { controls }\end{array}$ & $\begin{array}{l}\text { Explore whether early cART impacts } \\
\text { CD163 shedding, with possible } \\
\text { implications on the CNS. }\end{array}$ & sCD163 & $\begin{array}{l}\text { Early treatment reduces } \\
\text { sCD163 which is linked } \\
\text { to neuropsychological } \\
\text { perfomances }\end{array}$ & {$[32]$} \\
\hline $\begin{array}{l}\text { Neurogognitive } \\
\text { Impairment }\end{array}$ & Cross-sectional & $\begin{array}{l}90 \text { cART-treated, } 94 \\
\text { uninfected controls }\end{array}$ & $\begin{array}{l}\text { Assess the impact of HIV on } \\
\text { complex motor performances. }\end{array}$ & $\begin{array}{l}\text { d-dimer, IL-6, } \\
\text { MCP-1, sCD14, } \\
\text { TNF- } \alpha\end{array}$ & $\begin{array}{l}\text { Inflammation accounts } \\
\text { for worse complex motor } \\
\text { skills. }\end{array}$ & [36] \\
\hline Death & Case-control & $\begin{array}{l}64 \text { cases }-128 \text { controls } \\
\text { (LCOSA cohort) } \\
27 \text { cases }-54 \text { controls } \\
\text { (SCOPE cohort) }\end{array}$ & $\begin{array}{l}\text { Assess immunologic predictors of } \\
\text { mortality. }\end{array}$ & $\begin{array}{l}\text { IL-6, I-FABP, } \\
\text { sCD14, hs-CRP, } \\
\text { zonulin-1, sTNFR- } \\
1, \text { d-dimer, KT } \\
\text { ratio, T cell } \\
\text { activation } \\
\text { (CD38/HLA-DR), } \\
\text { exhaustion (PD1), } \\
\text { senescence } \\
(\text { CD57/CD28) }\end{array}$ & $\begin{array}{l}\text { Gut epithelial barrier } \\
\text { dysfunction, } \\
\text { immune } \\
\text { inflammate } \\
\text { independently } \\
\text { mortality }\end{array}$ & {$[52]$} \\
\hline SNAEs/death & $\begin{array}{l}\text { Case-control; } \\
\text { longitudinal }\end{array}$ & $\begin{array}{l}\text { cART-treated: } \\
143 \text { cases (non-AIDS events) } \\
315 \text { controls }\end{array}$ & $\begin{array}{l}\text { Assess the role of biomarkers on } \\
\text { disease outcomes. }\end{array}$ & $\begin{array}{l}\text { IL-6, IFN- } \gamma \text {, } \\
\text { sCD14, IP10, } \\
\text { sTNFR-1, sTNFR- } \\
\text { II, d-dimer } \\
\text { T cell activation } \\
\text { (CD38/HLA-DR), } \\
\text { exhaustion (PD1) } \\
\text { senescence } \\
\text { (CD57/CD28) }\end{array}$ & $\begin{array}{l}\text { IL-6, sTNFR-I and II, } \\
\text { sCD14,, plasma KT ratio, } \\
\text { and d-dimer level } \\
\text { associate with a higher } \\
\text { risk of non-AIDS-related } \\
\text { morbidity and mortality. }\end{array}$ & [72] \\
\hline SNAEs & Case-control; & cART-treated: & Investigate whether unchanged or & sCD14, sCD163, & Unchanged or slow rates & {$[83]$} \\
\hline
\end{tabular}




\begin{tabular}{|c|c|c|c|c|c|c|}
\hline & longitudinal & $\begin{array}{l}39 \text { cases (non-AIDS events) } \\
39 \text { controls }\end{array}$ & $\begin{array}{l}\text { smaller decreases in systemic } \\
\text { inflammation predict SNAEs. }\end{array}$ & IL-6 & $\begin{array}{l}\text { of decrease of sCD14 and } \\
\text { IL-6, levels predict } \\
\text { SNAEs. }\end{array}$ & \\
\hline SNAEs & Longitudinal & 249 cART-treated & $\begin{array}{l}\text { Examine the longitudinal changes in } \\
\text { biomarkers following cART their } \\
\text { association with future non-AIDS } \\
\text { events. }\end{array}$ & IL-6, d-dimer & $\begin{array}{l}\text { Persistent elevation of d- } \\
\text { dimer levels associate } \\
\text { with an increased risk of } \\
\text { non-AIDS events. }\end{array}$ & {$[43]$} \\
\hline SNAEs/death & Cross-sectional & $\begin{array}{l}3756 \text { cART-treated: } \\
\text { 1748 SMART, } 1446 \\
\text { ESPRIT, } 572 \text { SILCAAT } \\
\text { cohorts }\end{array}$ & $\begin{array}{l}\text { Examine the associations of } \\
\text { biomarkers with SNAEs/death in } 3 \\
\text { large cohorts. }\end{array}$ & $\begin{array}{l}\text { IL-6, d-dimer, hs- } \\
\text { CRP }\end{array}$ & $\begin{array}{l}\text { IL-6 and d-dimer are } \\
\text { independently associatee } \\
\text { with SNAEs. }\end{array}$ & [42] \\
\hline
\end{tabular}

\section{Legend:}

CVD, cardiovascular disease; cART, combination antiretroviral therapy; LPS, lipopolysaccharide; sCD14, soluble sCD14; hs-CRP, high-sensitivity C Reactive Protein; sCD163, soluble 163; sTNFR, soluble Tumor Necrosis Factor Receptor; sVCAM-1, vascular cell adhesion molecule-1; OPG, Osteoprotegerin; RANKL, RANK Ligand; TNF- $\alpha$, Tumor Necorsi Factor- $\alpha$; IL-, Interleukin; sICAM-1, intracellular adhesion molecule-1; IMT, Intima Media Thickness; CSF, Cerebro-spinal Fluid; NFL, Neurofilament Light protein; HAND, HIV-Associated Neurocognitive Disorder; MCP-1, Monocyte chemoattractant protein-1; IP-10, Interferon- $\gamma$-induced protein 10; IFN- $\gamma$, Interferon- $\gamma$; I-FABP, Intestinal fatty-acid binding protein; KT, Kynurenine tryptophan; SNAE, Serious Non-AIDS Event. 


\section{Conflict of Interests Statement}

On behalf of all authors, the corresponding author states that there is no conflict of interest. 


\section{References}

1. Klatt NR, Chomont N, Douek DC, Deeks SG. Immune activation and HIV persistence: implications for curative approaches to HIV infection. Immunol Rev 2013; 254:326-42.

2. Palella FJ, Delaney KM, Moorman AC, et al. Declining morbidity and mortality among patients with advanced human immunodeficiency virus infection. HIV Outpatient Study Investigators. N Engl J Med 1998; 338:853-60.

3. Tsoukas C. Immunosenescence and aging in HIV. Curr Opin HIV AIDS 2014; 9:398-404.

4. Steele AK, Lee EJ, Vestal B, et al. Contribution of intestinal barrier damage, microbial translocation and HIV-1 infection status to an inflammaging signature. PLoS One 2014; 9:e97171.

5. Duffau P, Ozanne A, Bonnet F, et al. Multimorbidity, age-related comorbidities and mortality: association of activation, senescence and inflammation markers in HIV adults. AIDS 2018; $32: 1651-60$.

6. Justice AC, Erlandson KM, Hunt PW, Landay A, Miotti P, Tracy RP. Can Biomarkers Advance HIV Research and Care in the Antiretroviral Therapy Era? J Infect Dis 2018; 217:521-8.

7. Brenchley JM, Price DA, Schacker TW, et al. Microbial translocation is a cause of systemic immune activation in chronic HIV infection. Nat Med 2006; 12:1365-71.

8. Jiang W, Lederman MM, Hunt P, et al. Plasma levels of bacterial DNA correlate with immune activation and the magnitude of immune restoration in persons with antiretroviral-treated HIV infection. J Infect Dis 2009; 199:1177-85.

9. Marchetti G, Bellistrì GM, Borghi E, et al. Microbial translocation is associated with sustained failure in CD4+ T-cell reconstitution in HIV-infected patients on long-term highly active antiretroviral therapy. AIDS 2008; 22:2035-8.

10. Longenecker CT, Sullivan C, Baker JV. Immune activation and cardiovascular disease in chronic HIV infection. Curr Opin HIV AIDS 2016; 11:216-25. 
11. Pedersen KK, Pedersen M, Trøseid M, et al. Microbial translocation in HIV infection is associated with dyslipidemia, insulin resistance, and risk of myocardial infarction. J Acquir Immune Defic Syndr 2013; 64:425-33.

12. Alcaide ML, Parmigiani A, Pallikkuth S, et al. Immune activation in HIV-infected aging women on antiretrovirals--implications for age-associated comorbidities: a cross-sectional pilot study. PLoS One 2013; 8:e63804.

13. Timmons T, Shen C, Aldrovandi G, et al. Microbial translocation and metabolic and body composition measures in treated and untreated HIV infection. AIDS Res Hum Retroviruses 2014; $30: 272-7$.

14. Pedersen KK, Manner IW, Seljeflot I, et al. Monocyte activation, but not microbial translocation, is independently associated with markers of endovascular dysfunction in HIVinfected patients receiving cART. J Acquir Immune Defic Syndr 2014; 67:370-4.

15. Mooney S, Tracy R, Osler T, Grace C. Elevated Biomarkers of Inflammation and Coagulation in Patients with HIV Are Associated with Higher Framingham and VACS Risk Index Scores. PLoS One 2015; 10:e0144312.

16. Bahrami H, Budoff M, Haberlen SA, et al. Inflammatory Markers Associated With Subclinical Coronary Artery Disease: The Multicenter AIDS Cohort Study. J Am Heart Assoc 2016; 5.

17. Hsu DC, Ma YF, Hur S, et al. Plasma IL-6 levels are independently associated with atherosclerosis and mortality in HIV-infected individuals on suppressive antiretroviral therapy. AIDS 2016; 30:2065-74.

18. McKibben RA, Margolick JB, Grinspoon S, et al. Elevated levels of monocyte activation markers are associated with subclinical atherosclerosis in men with and those without HIV infection. J Infect Dis 2015; 211:1219-28.

19. Longenecker CT, Jiang Y, Orringer CE, et al. Soluble CD14 is independently associated with coronary calcification and extent of subclinical vascular disease in treated HIV infection. AIDS 2014; 28:969-77. 
20. Hanna DB, Lin J, Post WS, et al. Association of Macrophage Inflammation Biomarkers With Progression of Subclinical Carotid Artery Atherosclerosis in HIV-Infected Women and Men. J Infect Dis 2017; 215:1352-61.

21. McGinty T, Mirmonsef P, Mallon PW, Landay AL. Does systemic inflammation and immune activation contribute to fracture risk in HIV? Curr Opin HIV AIDS 2016; 11:253-60.

22. Ofotokun I, Titanji K, Vikulina T, et al. Role of T-cell reconstitution in HIV-1 antiretroviral therapy-induced bone loss. Nat Commun 2015; 6:8282.

23. Ofotokun I, Titanji K, Vunnava A, et al. Antiretroviral therapy induces a rapid increase in bone resorption that is positively associated with the magnitude of immune reconstitution in HIV infection. AIDS 2016; 30:405-14.

24. Titanji K, Vunnava A, Sheth AN, et al. Dysregulated B cell expression of RANKL and OPG correlates with loss of bone mineral density in HIV infection. PLoS Pathog 2014; 10:e1004497.

25. Hileman CO, Labbato DE, Storer NJ, Tangpricha V, McComsey GA. Is bone loss linked to chronic inflammation in antiretroviral-naive HIV-infected adults? A 48-week matched cohort study. AIDS 2014; 28:1759-67.

26. Manavalan JS, Arpadi S, Tharmarajah S, et al. Abnormal Bone Acquisition With Early-Life HIV Infection: Role of Immune Activation and Senescent Osteogenic Precursors. J Bone Miner Res 2016; 31:1988-96.

27. Tincati C, Basilissi M, Sinigaglia E, et al. Invariant natural killer T (iNKT) cells in HAARTtreated, HIV-positive patients with bone and cardiovascular impairment. PLoS One 2014; 9:e110287.

28. D'Abramo A, Zingaropoli MA, Oliva A, et al. Higher Levels of Osteoprotegerin and Immune Activation/Immunosenescence Markers Are Correlated with Concomitant Bone and Endovascular Damage in HIV-Suppressed Patients. PLoS One 2016; 11:e0149601. 
29. Erlandson KM, O’Riordan M, Labbato D, McComsey GA. Relationships between inflammation, immune activation, and bone health among HIV-infected adults on stable antiretroviral therapy. J Acquir Immune Defic Syndr 2014; 65:290-8.

30. Kendall MA, Tassiopoulos K, McComsey GA, Yin MT. Fractures Are Not Associated with CD8(+) T Cell Activation: An Analysis of the ACTG ALLRT Study. AIDS Res Hum Retroviruses 2015; 31:769-71.

31. Rubin LH, Sacktor N, Creighton J, et al. Microglial activation is inversely associated with cognition in individuals living with HIV on effective antiretroviral therapy. AIDS 2018; 32:1661-7.

32. D'Antoni ML, Byron MM, Chan P, et al. Normalization of Soluble CD163 Levels After Institution of Antiretroviral Therapy During Acute HIV Infection Tracks with Fewer Neurological Abnormalities. J Infect Dis 2018; 218:1453-63.

33. Hsu DC, Sunyakumthorn P, Wegner M, et al. Central Nervous System Inflammation and Infection during Early, Nonaccelerated Simian-Human Immunodeficiency Virus Infection in Rhesus Macaques. J Virol 2018; 92.

34. Kessing CF, Spudich S, Valcour V, et al. High Number of Activated CD8+ T Cells Targeting HIV Antigens Are Present in Cerebrospinal Fluid in Acute HIV Infection. J Acquir Immune Defic Syndr 2017; 75:108-17.

35. Edén A, Marcotte TD, Heaton RK, et al. Increased Intrathecal Immune Activation in Virally Suppressed HIV-1 Infected Patients with Neurocognitive Impairment. PLoS One 2016; 11:e0157160.

36. Montoya JL, Campbell LM, Paolillo EW, et al. Inflammation Relates to Poorer Complex Motor Performance among Adults Living with HIV on Suppressive Antiretroviral Therapy. J Acquir Immune Defic Syndr 2018.

37. Jespersen S, Pedersen KK, Anesten B, et al. Soluble CD14 in cerebrospinal fluid is associated with markers of inflammation and axonal damage in untreated HIV-infected patients: a retrospective cross-sectional study. BMC Infect Dis 2016; 16:176. 
38. Ulfhammer G, Edén A, Mellgren $\AA$, et al. Persistent central nervous system immune activation following more than 10 years of effective HIV antiretroviral treatment. AIDS 2018; 32:2171-8.

39. Pérez-Santiago J, De Oliveira MF, Var SR, et al. Increased cell-free mitochondrial DNA is a marker of ongoing inflammation and better neurocognitive function in virologically suppressed HIV-infected individuals. J Neurovirol 2017; 23:283-9.

40. Marchetti G, Cozzi-Lepri A, Merlini E, et al. Microbial translocation predicts disease progression of HIV-infected antiretroviral-naive patients with high CD4+ cell count. AIDS 2011; 25:1385-94.

41. Sandler NG, Wand H, Roque A, et al. Plasma levels of soluble CD14 independently predict mortality in HIV infection. J Infect Dis 2011; 203:780-90.

42. Grund B, Baker JV, Deeks SG, et al. Relevance of Interleukin-6 and D-Dimer for Serious NonAIDS Morbidity and Death among HIV-Positive Adults on Suppressive Antiretroviral Therapy. PLoS One 2016; $11: \mathrm{e} 0155100$.

43. Freiberg MS, Bebu I, Tracy R, et al. D-Dimer Levels before HIV Seroconversion Remain Elevated Even after Viral Suppression and Are Associated with an Increased Risk of Non-AIDS Events. PLoS One 2016; 11:e0152588.

44. Nordell AD, McKenna M, Borges Á, et al. Severity of cardiovascular disease outcomes among patients with HIV is related to markers of inflammation and coagulation. J Am Heart Assoc 2014; 3:e000844.

45. McComsey GA, Kitch D, Sax PE, et al. Associations of inflammatory markers with AIDS and non-AIDS clinical events after initiation of antiretroviral therapy: AIDS clinical trials group A5224s, a substudy of ACTG A5202. J Acquir Immune Defic Syndr 2014; 65:167-74.

46. Tincati C, Douek DC, Marchetti G. Gut barrier structure, mucosal immunity and intestinal microbiota in the pathogenesis and treatment of HIV infection. AIDS Res Ther 2016; 13:19.

47. Nazli A, Chan O, Dobson-Belaire WN, et al. Exposure to HIV-1 directly impairs mucosal epithelial barrier integrity allowing microbial translocation. PLoS Pathog 2010; 6:e1000852. 
48. Perkins MR, Bartha I, Timmer JK, et al. The Interplay Between Host Genetic Variation, Viral Replication, and Microbial Translocation in Untreated HIV-Infected Individuals. J Infect Dis 2015; 212:578-84.

49. Chung CY, Alden SL, Funderburg NT, Fu P, Levine AD. Progressive proximal-to-distal reduction in expression of the tight junction complex in colonic epithelium of virally-suppressed HIV+ individuals. PLoS Pathog 2014; 10:e1004198.

50. Somsouk M, Estes JD, Deleage C, et al. Gut epithelial barrier and systemic inflammation during chronic HIV infection. AIDS 2015; 29:43-51.

51. Tincati C, Merlini E, Braidotti P, et al. Impaired gut junctional complexes feature late-treated individuals with suboptimal CD4+ T-cell recovery upon virologically suppressive combination antiretroviral therapy. AIDS 2016; 30:991-1003.

52. Hunt PW, Sinclair E, Rodriguez B, et al. Gut epithelial barrier dysfunction and innate immune activation predict mortality in treated HIV infection. J Infect Dis 2014; 210:1228-38.

53. Chamoun MN, Blumenthal A, Sullivan MJ, Schembri MA, Ulett GC. Bacterial pathogenesis and interleukin-17: interconnecting mechanisms of immune regulation, host genetics, and microbial virulence that influence severity of infection. Crit Rev Microbiol 2018; 44:465-86.

54. Song X, Dai D, He X, et al. Growth Factor FGF2 Cooperates with Interleukin-17 to Repair Intestinal Epithelial Damage. Immunity 2015; 43:488-501.

55. Lee JS, Tato CM, Joyce-Shaikh B, et al. Interleukin-23-Independent IL-17 Production Regulates Intestinal Epithelial Permeability. Immunity 2015; 43:727-38.

56. Maxwell JR, Zhang Y, Brown WA, et al. Differential Roles for Interleukin-23 and Interleukin17 in Intestinal Immunoregulation. Immunity 2015; 43:739-50.

57. Mudd JC, Brenchley JM. Gut Mucosal Barrier Dysfunction, Microbial Dysbiosis, and Their Role in HIV-1 Disease Progression. J Infect Dis 2016; 214 Suppl 2:S58-66.

58. Mudd JC, Brenchley JM. ILC You Later: Early and Irreparable Loss of Innate Lymphocytes in HIV Infection. Immunity 2016; 44:216-8. 
59. Vujkovic-Cvijin I, Dunham RM, Iwai S, et al. Dysbiosis of the gut microbiota is associated with HIV disease progression and tryptophan catabolism. Sci Transl Med 2013; 5:193ra91.

60. Gori A, Tincati C, Rizzardini G, et al. Early impairment of gut function and gut flora supporting a role for alteration of gastrointestinal mucosa in human immunodeficiency virus pathogenesis. $\mathbf{J}$ Clin Microbiol 2008; 46:757-8.

61. Dillon SM, Lee EJ, Kotter CV, et al. An altered intestinal mucosal microbiome in HIV-1 infection is associated with mucosal and systemic immune activation and endotoxemia. Mucosal Immunol 2014; 7:983-94.

62. Mutlu EA, Keshavarzian A, Losurdo J, et al. A compositional look at the human gastrointestinal microbiome and immune activation parameters in HIV infected subjects. PLoS Pathog 2014; 10:e1003829.

63. Vázquez-Castellanos JF, Serrano-Villar S, Latorre A, et al. Altered metabolism of gut microbiota contributes to chronic immune activation in HIV-infected individuals. Mucosal Immunol 2015; 8:760-72.

64. Lozupone CA, Li M, Campbell TB, et al. Alterations in the gut microbiota associated with HIV1 infection. Cell Host Microbe 2013; 14:329-39.

65. Villanueva-Millán MJ, Pérez-Matute P, Recio-Fernández E, Lezana Rosales JM, Oteo JA. Differential effects of antiretrovirals on microbial translocation and gut microbiota composition of HIV-infected patients. J Int AIDS Soc 2017; 20:21526.

66. Neff CP, Krueger O, Xiong K, et al. Fecal Microbiota Composition Drives Immune Activation in HIV-infected Individuals. EBioMedicine 2018; 30:192-202.

67. Serrano-Villar S, Moreno S, Ferrer M. The functional consequences of the microbiome in HIV: insights from metabolomic studies. Curr Opin HIV AIDS 2018; 13:88-94.

68. McHardy IH, Li X, Tong M, et al. HIV Infection is associated with compositional and functional shifts in the rectal mucosal microbiota. Microbiome 2013; 1:26. 
69. Serrano-Villar S, Rojo D, Martínez-Martínez M, et al. Gut Bacteria Metabolism Impacts Immune Recovery in HIV-infected Individuals. EBioMedicine 2016; 8:203-16.

70. Vujkovic-Cvijin I, Swainson LA, Chu SN, et al. Gut-Resident Lactobacillus Abundance Associates with IDO1 Inhibition and Th17 Dynamics in SIV-Infected Macaques. Cell Rep 2015.

71. Serrano-Villar S, Rojo D, Martínez-Martínez M, et al. HIV infection results in metabolic alterations in the gut microbiota different from those induced by other diseases. Sci Rep 2016; 6:26192.

72. Tenorio AR, Zheng Y, Bosch RJ, et al. Soluble markers of inflammation and coagulation but not T-cell activation predict non-AIDS-defining morbid events during suppressive antiretroviral treatment. J Infect Dis 2014; 210:1248-59.

73. Srinivasa S, Fitch KV, Lo J, et al. Plaque burden in HIV-infected patients is associated with serum intestinal microbiota-generated trimethylamine. AIDS 2015; 29:443-52.

74. Shan Z, Clish CB, Hua S, et al. Gut Microbial-Related Choline Metabolite Trimethylamine-NOxide Is Associated With Progression of Carotid Artery Atherosclerosis in HIV Infection. J Infect Dis 2018; 218:1474-9.

75. Haissman JM, Knudsen A, Hoel H, et al. Microbiota-Dependent Marker TMAO Is Elevated in Silent Ischemia but Is Not Associated With First-Time Myocardial Infarction in HIV Infection. J Acquir Immune Defic Syndr 2016; 71:130-6.

76. Miller PE, Haberlen SA, Brown TT, et al. Brief Report: Intestinal Microbiota-Produced Trimethylamine-N-Oxide and Its Association With Coronary Stenosis and HIV Serostatus. J Acquir Immune Defic Syndr 2016; 72:114-8.

77. Haissman JM, Haugaard AK, Ostrowski SR, et al. Microbiota-dependent metabolite and cardiovascular disease marker trimethylamine-N-oxide (TMAO) is associated with monocyte activation but not platelet function in untreated HIV infection. BMC Infect Dis 2017; 17:445. 
78. Missailidis C, Neogi U, Stenvinkel P, Trøseid M, Nowak P, Bergman P. The microbial metabolite trimethylamine-N-oxide in association with inflammation and microbial dysregulation in three HIV cohorts at various disease stages. AIDS 2018; 32:1589-98.

79. Carabotti M, Scirocco A, Maselli MA, Severi C. The gut-brain axis: interactions between enteric microbiota, central and enteric nervous systems. Ann Gastroenterol 2015; 28:203-9.

80. Alakkas A, Ellis RJ, Watson CW, et al. White matter damage, neuroinflammation, and neuronal integrity in HAND. J Neurovirol 2018.

81. McGinty T, Mallon PWG. Fractures and the gut microbiome. Curr Opin HIV AIDS 2018; $13: 28-37$.

82. Serrano-Villar S, de Lagarde M, Vázquez-Castellanos J, et al. Effects of Immunonutrition in Advanced HIV Disease: a Randomized Placebo Controlled Clinical Trial (Promaltia Study). Clin Infect Dis 2018.

83. Sunil M, Nigalye M, Somasunderam A, et al. Unchanged Levels of Soluble CD14 and IL-6 Over Time Predict Serious Non-AIDS Events in HIV-1-Infected People. AIDS Res Hum Retroviruses 2016; 32:1205-9. 